Provided for non-commercial research and education use. Not for reproduction, distribution or commercial use.

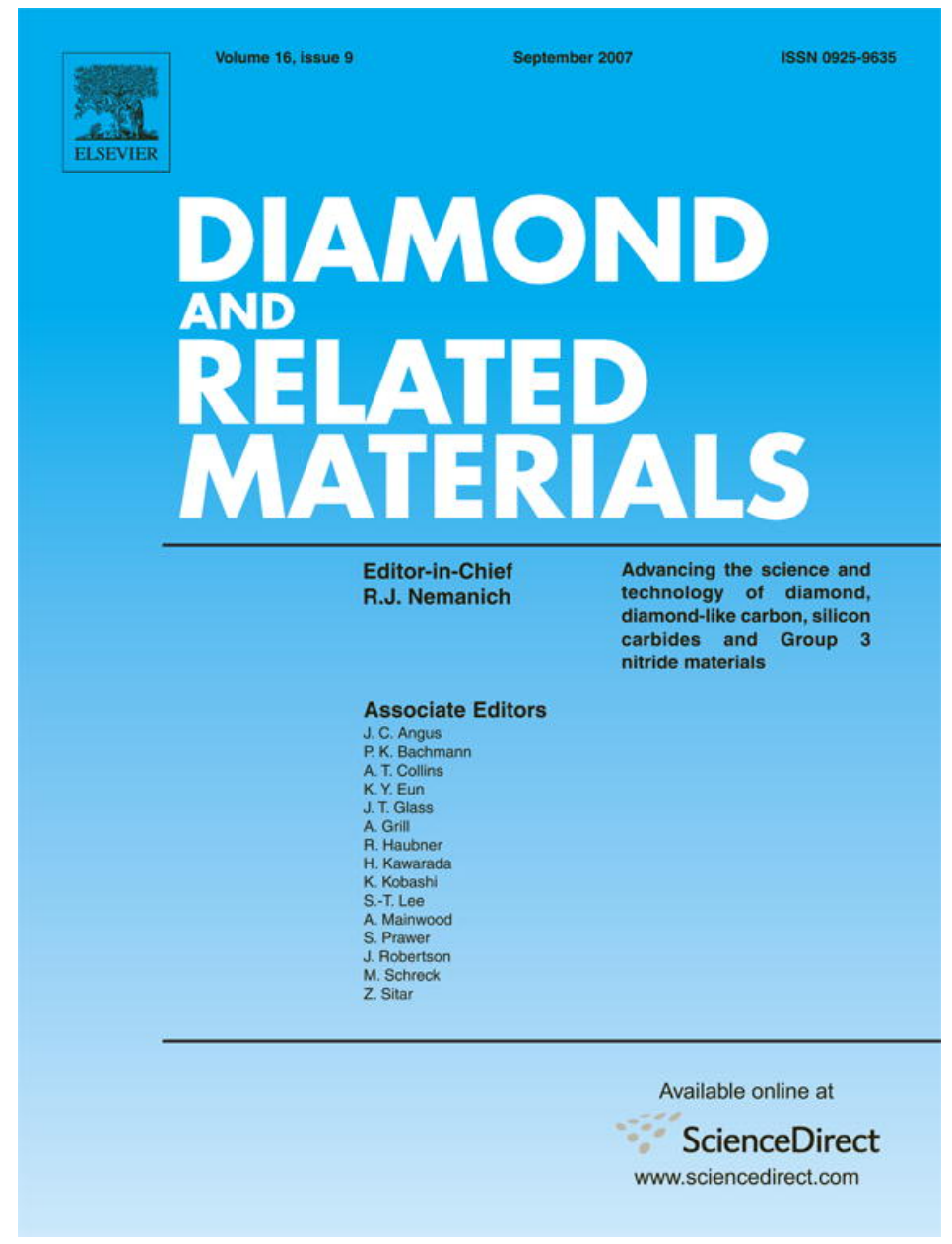

This article was published in an Elsevier journal. The attached copy

is furnished to the author for non-commercial research and education use, including for instruction at the author's institution, sharing with colleagues and providing to institution administration.

Other uses, including reproduction and distribution, or selling or licensing copies, or posting to personal, institutional or third party websites are prohibited.

In most cases authors are permitted to post their version of the article (e.g. in Word or Tex form) to their personal website or institutional repository. Authors requiring further information regarding Elsevier's archiving and manuscript policies are encouraged to visit:

http://www.elsevier.com/copyright 


\title{
Surface energy of the plasma treated Si incorporated diamond-like carbon films
}

\author{
Ritwik K. Roy, Heon-Woong Choi, Se-Jun Park, Kwang-Ryeol Lee* \\ Future Fusion Technology Laboratory, Korea Institute of Science and Technology, P.O. Box, 131, Cheongryang, Seoul, 130-650, South Korea
}

Received 8 November 2006; received in revised form 21 February 2007; accepted 13 June 2007

Available online 21 June 2007

\begin{abstract}
Surface energy and surface chemical bonds of the plasma treated Si incorporated diamond-like carbon films (Si-DLC) were investigated. The Si-DLC films were prepared by r.f. plasma assisted chemical vapor deposition using benzene and diluted silane $\left(\mathrm{SiH}_{4} / \mathrm{H}_{2}=10: 90\right)$ as the precursor gases. The Si-DLC films were subjected to plasma treatment using various gases like $\mathrm{N}_{2}, \mathrm{O}_{2}, \mathrm{H}_{2}$ and $\mathrm{CF}_{4}$. The plasma treated Si-DLC films showed a wide range of water contact angles from $13.4^{\circ}$ to $92.1^{\circ}$. The surface energies of the plasma treated Si-DLC films revealed a high polar component for $\mathrm{O}_{2}$ plasma treated Si-DLC films and a low polar component for $\mathrm{CF}_{4}$ plasma treated Si-DLC films. The $\mathrm{CF}_{4}$ plasma treated Si-DLC films indicated the minimum surface energy. X-ray photoelectron spectroscopy (XPS) revealed that the polarizability of the bonds present on the surface explains the hydrophilicity and hydrophobicity of the plasma treated Si-DLC films. We also suggest that the $\mathrm{O}_{2}$ plasma treated surface can provide an excellent hemocompatible surface from the estimated interfacial energy between the plasma treated Si-DLC surface and human blood. (C) 2007 Elsevier B.V. All rights reserved.
\end{abstract}

Keywords: Diamond-like carbon; Surface energy; Surface treatment

\section{Introduction}

Surface energy of a material plays an important role in controlling its properties and applications. Depending on situations, hydrophilicity of a material surface is desired for various coatings, adhesives and paints while surface hydrophobicity is required for ship hulls, contact lens, antisticking layers for lithographic application, self cleaning and water repellant surfaces. Surface properties of diamond-like carbon film have also drawn much attention due to its variety of applications ranging from machining tools, plastic mold to orthopedic implants [1]. Surface modified DLC coatings were found to improve the biocompatibility, lubricity and stability, which are significant in mechanical, biomedical and electronic applications [2-8]. Surface modification of DLC coatings have been done by doping with suitable elements [9-12], ion implantation [13] and plasma or ion beam processing [14]. Because of chemically active species in the plasma and the ease of the processing, the plasma treatment is the most widely used to modify the surface.

In this report the effect of plasma treatment on the surface energy of Si incorporated DLC (Si-DLC) films were investigated. It was reported that the $\mathrm{Si}$ incorporation into amorphous carbon

\footnotetext{
* Corresponding author.

E-mail address: krlee@kist.re.kr (K.-R. Lee).
}

network has advantages of reduced residual compressive stress [12], reduced humidity dependence of the tribological behavior [15], better corrosion resistance [16] and improved mechanical stability in aqueous environment [17]. It is thus believed that SiDLC film is a strong candidate for various protective surface coatings including biomedical implants [18,19]. However, a systematic investigation on the surface modification of Si-DLC film is yet to be found. The Si-DLC films were treated with plasma of various gases like $\mathrm{N}_{2}, \mathrm{O}_{2}, \mathrm{H}_{2}$ and $\mathrm{CF}_{4}$ for surface modification, which were subjected to wetting angle measurement and XPS analysis. The plasma treatment changed the surface energy in wide range depending on the treatment gas. Atomic bond structure and composition were investigated in depth to observe the correlation with the surface energy. The prospects of these surface modified Si-DLC films for hemocompatible applications are also discussed by estimating the interfacial energy between the modified surface and human blood.

\section{Experimental}

\subsection{Film preparation}

The Si-DLC films were prepared by $13.56 \mathrm{MHz}$ rf plasma assisted chemical vapor deposition (PACVD) technique. P type $\mathrm{Si}$ (100) was used as the substrate material. The substrates were 
placed on water cooled cathode where the r.f. power was delivered through impedance matching network. The precursor gases used in the deposition process were benzene and diluted silane $\left(\mathrm{SiH}_{4} / \mathrm{H}_{2}=10: 90\right)$. Prior to deposition, the substrates were sputter cleaned with Ar plasma for $15 \mathrm{~min}$ at the bias voltage of $-400 \mathrm{~V}$ and the pressure of $0.49 \mathrm{~Pa}$. An initial interlayer of a-Si:H was deposited on the substrates for better adhesion of the Si-DLC films. The Si-DLC films were then deposited at the bias voltage of $-400 \mathrm{~V}$ and the deposition pressure of $1.33 \mathrm{~Pa}$. The film thickness was $(0.55 \pm 0.01) \mu \mathrm{m}$ as measured by an alpha step profilometer. The Si concentration in the films was 2 at.\% as measured by Rutherford backscattering spectroscopy (RBS). The structure and properties of the Si-DLC film were reported previously [12].

The surface modification of the Si-DLC films was made by exposing the coated specimen to plasma of various gases like $\mathrm{N}_{2}, \mathrm{O}_{2}, \mathrm{H}_{2}$ and $\mathrm{CF}_{4}$. The plasma treatment of the Si-DLC films was performed for $10 \mathrm{~min}$ at a bias voltage of $-400 \mathrm{~V}$ and the pressure $1.33 \mathrm{~Pa}$. The film thicknesses were not varied significantly by the plasma treatments except the case of $\mathrm{O}_{2}$ plasma. The Si-DLC film was considerably etched by the $\mathrm{O}_{2}$ plasma, where the film thickness decreased to $0.31 \mu \mathrm{m}$.

\subsection{Surface energy measurement}

Owens method was used to determine the surface energy of the samples [20]. Wetting of a solid surface by a liquid is given by Young equation:

$\cos \theta \gamma_{\mathrm{lv}}=\gamma_{\mathrm{sv}}-\gamma_{\mathrm{sl}}-\pi_{\mathrm{e}}$,

where $\theta$ is the contact angle between the solid and liquid, $\gamma_{\mathrm{lv}}$, $\gamma_{\mathrm{sv}}$ are the free energies of the liquid and solid against their saturated vapor, $\gamma_{\mathrm{sl}}$ is the free energy of the interface between solid and liquid and $\pi_{\mathrm{e}}$ is the equilibrium pressure of adsorbed vapor of the liquid on solid. One can assume $\pi_{\mathrm{e}}=0$ in most cases. The surface or interfacial free energy can be resolved into dispersive and polar components:

$\gamma_{\mathrm{lv}}=\gamma_{\mathrm{lv}}^{d}+\gamma_{\mathrm{lv}}^{p}$

$\gamma_{\mathrm{sv}}=\gamma_{\mathrm{sv}}^{d}+\gamma_{\mathrm{sv}}^{p}$

$\gamma_{\mathrm{s} 1}=\gamma_{\mathrm{sl}}^{d}+\gamma_{\mathrm{s} l}^{p}$

where the superscripts $d$ and $p$ refer to the dispersive and polar components respectively. Expressing the Young equation as

$(1+\cos \theta) \gamma_{\mathrm{lv}}=\gamma_{\mathrm{sv}}-\gamma_{\mathrm{sl}}+\gamma_{\mathrm{lv}}$

and applying Eq. (2), we obtain

$(1+\cos \theta) \gamma_{\mathrm{lv}}=\left(\gamma_{\mathrm{sv}}^{d}-\gamma_{\mathrm{sl}}^{d}+\gamma_{\mathrm{lv}}^{d}\right)+\left(\gamma_{\mathrm{sv}}^{p}-\gamma_{\mathrm{sl}}^{p}+\gamma_{\mathrm{lv}}^{p}\right)$

The dispersive component of the interfacial tension between solid and liquid is given by the Good-Girifalco-Fowkes combining rule $[21,22]$ :

$\gamma_{\mathrm{sl}}^{d}=\gamma_{\mathrm{sv}}^{d}+\gamma_{\mathrm{lv}}^{d}-2 \sqrt{\gamma_{\mathrm{sv}}^{d} \gamma_{\mathrm{lv}}^{d}}$
If the polar component of the interfacial tension is expressed in a similar way to that of the dispersive component as shown by van Oss et al. [23],

$\gamma_{\mathrm{sl}}^{p}=\gamma_{\mathrm{sv}}^{p}+\gamma_{\mathrm{lv}}^{p}-2 \sqrt{\gamma_{\mathrm{sv}}^{p} \gamma_{\mathrm{lv}}^{p}}$

By inserting Eqs. (5) and (6) into Eq. (4), the following expression can be derived from the Young equation:

$1+\cos \theta=2\left(\frac{\sqrt{\gamma_{\mathrm{sv}}^{d}} \sqrt{\gamma_{\mathrm{lv}}^{d}}}{\gamma_{\mathrm{lv}}}+\frac{\sqrt{\gamma_{\mathrm{sv}}^{p}} \sqrt{\gamma_{\mathrm{lv}}^{p}}}{\gamma_{\mathrm{lv}}}\right)$,

which can be written as:

$1+\cos \theta=\frac{2}{\gamma_{l v}}\left(\alpha_{\mathrm{s}} \alpha_{1}+\beta_{\mathrm{s}} \beta_{1}\right)$

where

$\alpha_{\mathrm{s}}=\sqrt{\gamma_{\mathrm{sv}}^{d}}, \alpha_{1}=\sqrt{\gamma_{\mathrm{lv}}^{d}}, \beta_{\mathrm{s}}=\sqrt{\gamma_{\mathrm{sv}}^{p}}$ and $\beta_{1}=\sqrt{\gamma_{\mathrm{lv}}^{p}}$

By measuring the $\theta$ of two different liquids with known values of $\gamma_{\mathrm{lv}}{ }^{d}$ and $\gamma_{\mathrm{lv}}{ }^{p}$, one can obtain the $\gamma_{\mathrm{sv}}{ }^{d}$ and ${\gamma_{\mathrm{sv}}}^{p}$ values of a solid surface by solving the simultaneous equations. In the present work, deionised water and formamide were used [20]. The contact angles of the films were measured by a contact angle goniometer (Rame-Hart. Inc.). An average of 10 measurements was taken to determine the contact angle value.

\subsection{X-ray photoelectron spectroscopy measurements}

XPS measurements were performed by Physical Electronics PHI 5800 ESCA system. Al $\mathrm{K} \alpha$ at $1486.6 \mathrm{eV}$ was used as the $\mathrm{X}$-Ray source, while the anode is maintained at $250 \mathrm{~W}, 10 \mathrm{kV}$ and $27 \mathrm{~mA}$. The peak position calibrations were done by taking $\mathrm{C} 1 \mathrm{~s}$ peak at $284.6 \mathrm{eV}$. The vacuum in the XPS chamber were less than $2 \times 10^{-8} \mathrm{~Pa}$, and the spot size of the beam was $400 \mu \mathrm{m} \times 400 \mu \mathrm{m}$. The curve fittings were carried out with a mixture of Gaussian and Lorentzian function. The surface elemental (ith element) compositions were calculated from the peak areas $\left(A_{i}\right)$ of individual peaks and using their corresponding atomic sensitivity factor $\left(f_{i}\right)$ [24]. Uncertainty of the quantitative value of the composition was estimated to be 0.5 at. $\%$.

\section{Results and discussion}

\subsection{Surface energy and wettability}

The water contact angles of the plasma treated Si-DLC films varied over a wide range from $13.4^{\circ}$ to $92.1^{\circ}$ as shown in Fig. 1. A hydrophobic surface was obtained in case of $\mathrm{CF}_{4}$ plasma treated Si-DLC films while a hydrophilic surface was observed for $\mathrm{O}_{2}$ plasma treated films. Fig. 2 shows the dispersive and polar components of surface energies of the films determined by 


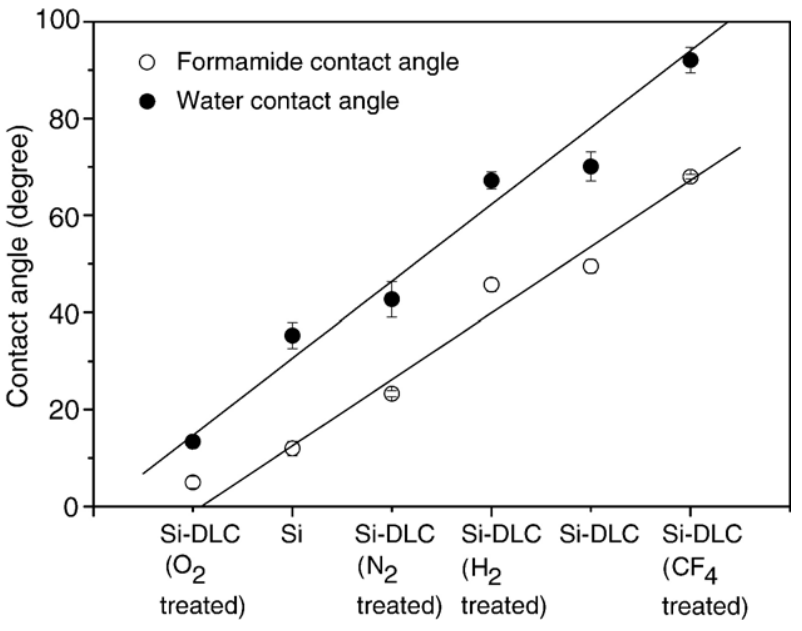

Fig. 1. Water and formamide contact angles of Si substrates, Si-DLC films and plasma treated Si-DLC films.

Eq. (7). The Si substrates revealed a higher polar component in their surface energies, presumably due to the native silicon oxide layer on the surface. Si-DLC coating slightly increased the dispersive component but significantly decreased the polar component. Plasma surface treatment of the coating didn't change the dispersive component in a considerable scale except the $\mathrm{O}_{2}$ plasma treatment. However, polar component was strongly dependent on the treatment condition. The polar component decreased considerably by $\mathrm{CF}_{4}$ plasma treatment. It was observed that the surface properties after the $\mathrm{H}_{2}$ plasma treatment are essentially the same as that of as deposited SiDLC film. In contrast, $\mathrm{N}_{2}$ plasma treatment increased the polar component. The most significant change occurred when treated by $\mathrm{O}_{2}$ plasma. The polar component becomes approximately 5 times larger than that of as deposited Si-DLC film, while the dispersive components decreased to half of the untreated value. A clear correlation was also observed between the polar component in the surface energy and their wettability of water as can be seen in Fig. 3. The water contact angle monotonically decreased as the polar component in the surface energy

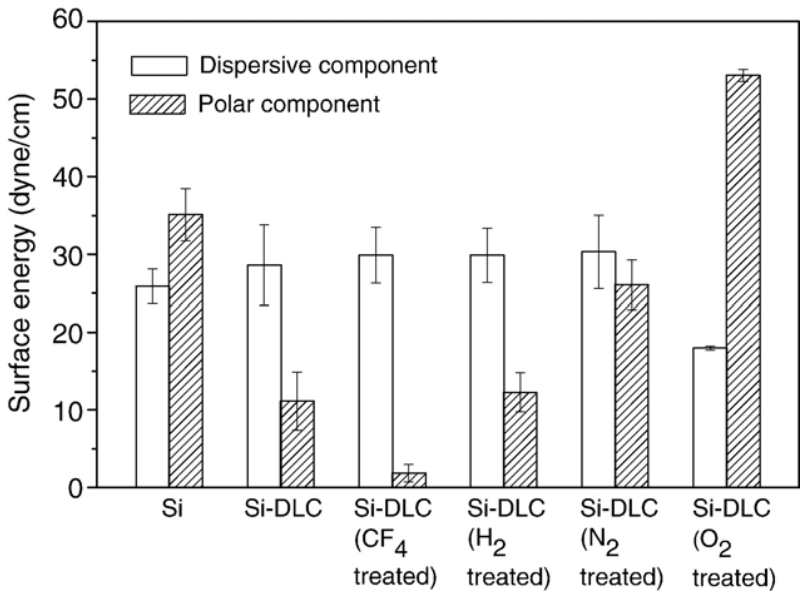

Fig. 2. Polar and dispersive component of surface energies of Si substrates, SiDLC films and plasma treated Si-DLC films.

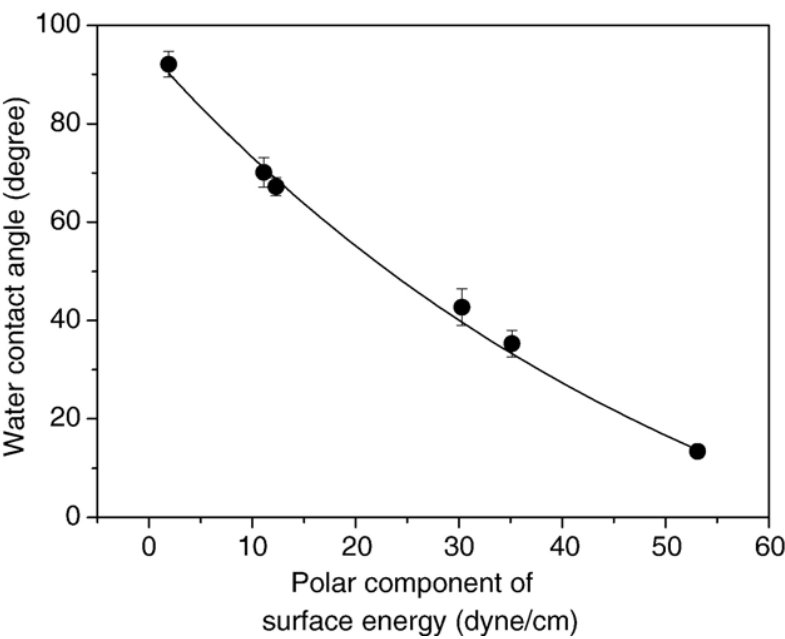

Fig. 3. Variation of water contact angles of the Si substrates, Si-DLC films and plasma treated Si-DLC films with polar component of their surface energies.

increased. Electric dipole of water molecule would be attracted by the polar component, which reduces the interfacial energy between the surface and water and thus the wetting angle of water.

\subsection{X-ray photoelecron spectroscopy (XPS) studies}

XPS was used to determine the chemical bonds present on the surfaces of Si-DLC and plasma treated Si-DLC films. Figs. 4 and 5 respectively showed the XPS spectra of as deposited Si-DLC and plasma treated Si-DLC films in the C 1s, Si 2p and selected $\mathrm{F} 1 \mathrm{~s}, \mathrm{~N} 1 \mathrm{~s}$ and $\mathrm{O} 1 \mathrm{~s}$ binding energy region. A small amount of oxygen was observed in all the films due to exposure of the samples in ambient air before XPS measurement. The surface composition of the Si-DLC and plasma treated Si-DLC films as determined from XPS analysis are shown in Table 1.

Fig. 4(a) and (b) showed the deconvoluted XPS spectra of SiDLC films in the $\mathrm{C} 1 \mathrm{~s}$ and $\mathrm{Si} 2 \mathrm{p}$ binding energy region respectively. The $\mathrm{C} 1 \mathrm{~s}$ spectrum denoted the presence of a large peak for $\mathrm{sp}^{2} \mathrm{C}=\mathrm{C}$ bond at $284.4 \mathrm{eV}$ and a small one at $285.1 \mathrm{eV}$ for $\mathrm{sp}^{3} \mathrm{C}-\mathrm{C}$ bond on the surface. These binding energy values are similar with those reported in Ref. $[25,26]$. It indicates that the surfaces of Si-DLC films are rich in $\mathrm{sp}^{2}$ bonded carbon. Another peak at $292.7 \mathrm{eV}$ was attributed to $\pi$-excitation, which appears in all carbon compounds having double bonds [27-29]. The Si $2 \mathrm{p}$ spectrum was deconvoluted into five components with a strong peak for $\mathrm{Si}-\mathrm{C}(\mathrm{Si} 1+)$ bond at $100.7 \mathrm{eV}$ and two small peaks for $\mathrm{Si}_{2} \mathrm{O}_{3}(\mathrm{Si} 3+)$ and $\mathrm{SiO}_{2}(\mathrm{Si} 4+)$ type of binding at $102.3 \mathrm{eV}$ and $103.4 \mathrm{eV}$ respectively (the number in bracket denotes the oxidation state of Si). Other small peaks at $104.5 \mathrm{eV}$ and $107 \mathrm{eV}$ could not be identified. The binding energies of $\mathrm{Si}-\mathrm{C}$ and $\mathrm{SiO}_{2}$ are in agreement with those found in Ref. [30-32]. The peak at $102.3 \mathrm{eV}$ was attributed to an intermediate oxidation state of $\mathrm{Si}, \mathrm{Si}_{2} \mathrm{O}_{3}(\mathrm{Si} 3+)$ as observed by Atanassova et al. [32]. The Si $2 p$ spectrum denotes that the incorporated $\mathrm{Si}$ in a-C:H films are mainly bonded with carbon network. The elemental composition of Table 1 revealed that $\mathrm{Si}$ was present on the surface in 2.0 at.\%. 

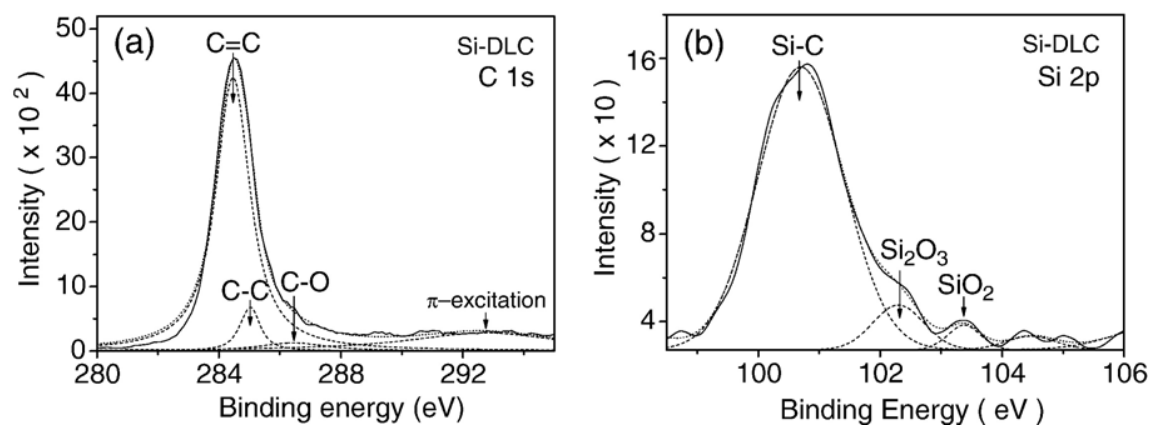

Fig. 4. XPS spectra of Si-DLC film in C 1s and Si 2p binding energy region.

$\mathrm{H}_{2}$ plasma treatment didn't change the XPS spectra in a considerable scale. However, the surface structure of the Si-DLC films undergoes significant changes with $\mathrm{CF}_{4}$ plasma treatment. Fig. 5(a), (b) and (c) respectively showed the C 1s, Si 2p and F $1 \mathrm{~s}$ XPS spectra of the $\mathrm{CF}_{4}$ plasma treated Si-DLC film. The $\mathrm{C} 1 \mathrm{~s}$ spectrum was deconvoluted into five components at 284.4, 285.2, $287.5,289.5,290.8$ and $293.5 \mathrm{eV}$. These peak positions can be assigned to the binding energy of $\mathrm{C}=\mathrm{C}, \mathrm{C}-\mathrm{C}, \mathrm{C}-\mathrm{CF}, \mathrm{CF}-\mathrm{CF}_{n}$,
$\mathrm{CF}_{2}$ and $\mathrm{CF}_{3}$ bonded network respectively. The binding energies of these peaks are in agreement with those reported for fluorinated amorphous carbon films [33-36]. A large peak was obtained for $\mathrm{sp}^{3}$ bonded carbon $(\mathrm{C}-\mathrm{C})$ compared to $\mathrm{sp}^{2}$ bonded one $(\mathrm{C}=\mathrm{C})$. It denotes that $\mathrm{CF}_{4}$ plasma treatment has enhanced the $\mathrm{sp}^{3}$ fraction in the films. Because fluorine is a monovalent element and do not form double bonds, they compel carbon into a $\mathrm{sp}^{3}$ bonded network [37]. Fluorine would be incorporated into the carbon
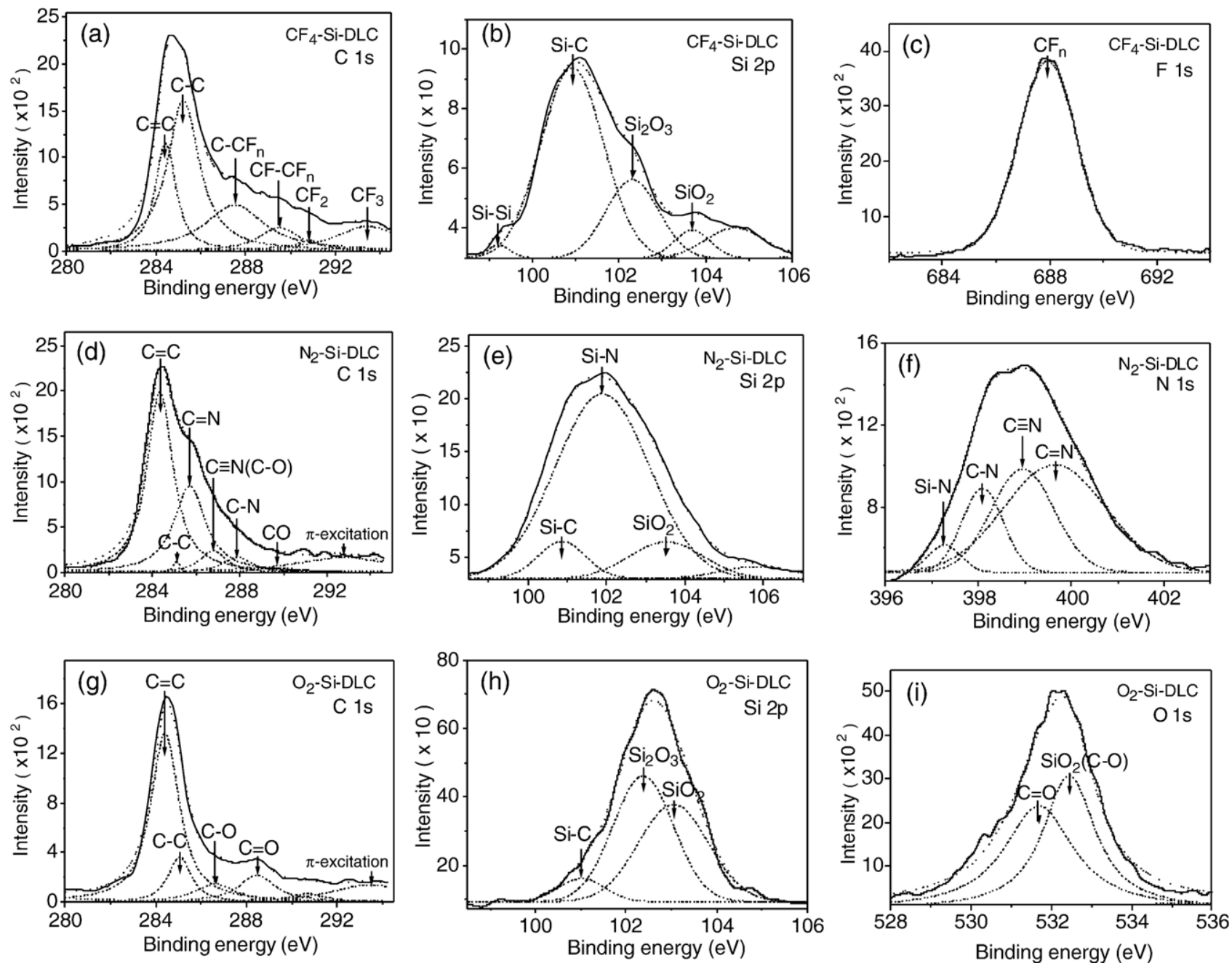

Fig. 5. XPS spectra of $\mathrm{CF}_{4}, \mathrm{~N}_{2}$ and $\mathrm{O}_{2}$ plasma treated Si-DLC films in $\mathrm{C} 1 \mathrm{~s}, \mathrm{Si} 2 \mathrm{p}$ and selective F 1s, N 1s and O 1s binding energy region (CF $-\mathrm{Si}-\mathrm{DLC}, \mathrm{N}_{2}-\mathrm{Si}-\mathrm{DLC}$, and $\mathrm{O}_{2}$-Si-DLC represents $\mathrm{CF}_{4}, \mathrm{~N}_{2}$ and $\mathrm{O}_{2}$ plasma treated Si-DLC films respectively). (a,b,c) C 1s, Si 2p and F1s spectra of CF 4 plasma treated Si-DLC film. (d,e,f) C 1s, Si $2 \mathrm{p}$ and N1s spectra of $\mathrm{N}_{2}$ plasma treated Si-DLC film. (g,h,i) C 1s, Si 2p and O1s spectra of $\mathrm{O}_{2}$ plasma treated Si-DLC film. 
Table 1

Surface composition of Si-DLC and plasma treated Si-DLC films determined by XPS

\begin{tabular}{llllll}
\hline Films & C (at.\%) & Si (at.\%) & O (at.\%) & N (at.\%) & F (at.\%) \\
\hline Si-DLC & 92.8 & 2.0 & 5.3 & - & - \\
Si-DLC $\left(\mathrm{H}_{2}\right.$ treated) & 91.4 & 2.9 & 5.7 & - & - \\
Si-DLC $\left(\mathrm{CF}_{4}\right.$ treated) & 78.0 & 1.1 & 0.4 & - & 20.5 \\
Si-DLC $\left(\mathrm{N}_{2}\right.$ treated) & 76.5 & 4.5 & 4.5 & 14.5 & - \\
Si-DLC $\left(\mathrm{O}_{2}\right.$ treated) & 43.7 & 8.0 & 48.3 & - & - \\
\hline
\end{tabular}

network by breaking the $\mathrm{C}-\mathrm{H}$ bond and substituting the $\mathrm{H}$ atoms. Sah et al. have observed by infrared spectroscopy that with increase in fluorine concentration in the RF plasma deposited a-C: $\mathrm{H}$ films, there is a significant reduction in $\mathrm{C}-\mathrm{H}$ bonds accompanied by an increase in $\mathrm{C}-\mathrm{F}$ bonds [38]. Fig. 5(a) revealed significant amount of $\mathrm{C}-\mathrm{CF}_{n}$ and $\mathrm{CF}-\mathrm{CF}_{n}$ bonding on the surface. These bonding denote the formation of polymeric compounds $\left(\mathrm{CF}_{n}\right)_{x}$ with $\mathrm{CF}_{4}$ plasma treatment.

In the plasma state, $\mathrm{CF}_{4}$ can dissociate in the following manner [39]:

$$
\begin{aligned}
& \mathrm{CF}_{4}+e^{-} \rightarrow \mathrm{CF}_{3}+\mathrm{F}(\Delta \mathrm{H}=119 \mathrm{kcal} / \mathrm{mol}) \\
& \mathrm{CF}_{4}+e^{-} \rightarrow \mathrm{CF}_{2}+\mathrm{F}_{2}(\Delta \mathrm{H}=169 \mathrm{kcal} / \mathrm{mol}) .
\end{aligned}
$$

The above equations show that the lower enthalpy value will favor the formation of $\mathrm{CF}_{3}^{+}$radicals from $\mathrm{CF}_{4}$ plasma. In the $\mathrm{C}$ $1 \mathrm{~s}$ XPS spectra, the peak intensity and FWHM for $\mathrm{CF}_{3}$ binding peak was higher compared to $\mathrm{CF}_{2}$ binding peak. It denotes that the formation of $\mathrm{CF}_{3}$ bonded network might have resulted from the $\mathrm{CF}_{3}^{+}$radicals in the $\mathrm{CF}_{4}$ plasma.

The deconvoluted Si 2p spectrum (Fig. 5(b)) was dominated by a broad peak for $\mathrm{Si}-\mathrm{C}(\mathrm{Si} 1+)$ bonding at $100.9 \mathrm{eV}$. Two small peaks at 102.3 and $103.7 \mathrm{eV}$ are assigned to $\mathrm{Si}$ binding in $\mathrm{Si}_{2} \mathrm{O}_{3}$ $(\mathrm{Si} 3+)$ and $\mathrm{SiO}_{2}(\mathrm{Si} 4+)$ respectively [30-32]. These two peaks have resulted from exposure of the samples to ambient air between film synthesis and XPS measurements. A very small peak at $99.1 \mathrm{eV}$ was also observed for $\mathrm{Si}-\mathrm{Si}(\mathrm{Si} 0+$ ) bonding. Another peak at $104.7 \mathrm{eV}$ could not be identified. The F 1s spectrum (Fig. 5(c)) consisted of a large and symmetric peak located at $687.9 \mathrm{eV}$ which was attributed to $\mathrm{CF}_{n}$ bondings [36]. The elemental composition in Table 1 showed that $\mathrm{CF}_{4}$ plasma treatment have etched away a significant amount of carbon and silicon, whereas fluorine was incorporated in the films in high percentage by forming $\mathrm{CF}_{n}$ network. The $\mathrm{CF}_{4}$ plasma treated $\mathrm{Si}$ DLC films are also found to be less susceptible to air exposure as is evident from the small amount of oxygen on the film surface.

The $\mathrm{N}_{2}$ plasma treatment also changed the surface bond characteristics of the Si-DLC films. The C 1s spectrum (Fig. 5 (d)) was decomposed into seven components at 284.4, 285.2, 285.7, 286.8, 287.9, 289.7 and $292.8 \mathrm{eV}$. These peak values are attributed to $\mathrm{C}=\mathrm{C}, \mathrm{C}-\mathrm{C}, \mathrm{C}=\mathrm{N}, \mathrm{C} \equiv \mathrm{N}(\mathrm{C}-\mathrm{O}), \mathrm{C}-\mathrm{N}, \mathrm{CO}$ bonded network and $\pi$-excitation respectively and are similar with other reports $[29,40,41]$. The spectrum showed that the peak intensity for $\mathrm{sp}^{3}$ bonded carbon $(\mathrm{C}-\mathrm{C})$ has reduced significantly. It indicates that the surface structure has become more graphitized with nitrogen incorporation into the surface. Mansour and Ugolini have also observed that nitrogen incorporation in amorphous hydrogenated carbon films favors graphitization [42]. From He I UPS valence band spectra, they noted increase in area and width of the $p-\pi$ density of states (DOS) with increasing nitrogen content which is in accordance with the increase in size of the graphite like island due to clustering of $\pi$ states in the aromatic rings. The $\mathrm{C} 1 \mathrm{~s}$ spectrum also revealed that nitrogen was preferentially bonded with carbon as $\mathrm{sp}^{2}$ $\mathrm{C}=\mathrm{N}$ and $\mathrm{sp} \mathrm{C} \equiv \mathrm{N}$ bonding compared to $\mathrm{sp}^{3} \mathrm{C}-\mathrm{N}$ bonding. The binding energy peak of $\mathrm{C} \equiv \mathrm{N}$ bond is coincident with that of $\mathrm{C}-\mathrm{O}$ bond which denotes that the peak at $286.8 \mathrm{eV}$ has contribution of both $\mathrm{C} \equiv \mathrm{N}$ and $\mathrm{C}-\mathrm{O}$ bonded network.

Si $2 p$ spectrum (Fig. 5(e)) was deconvoluted into four components at 100.9, 101.9, 103.5 and $105.8 \mathrm{eV}$. The first three peaks are related to the binding energies of $\mathrm{Si}-\mathrm{C}(\mathrm{Si} 1+), \mathrm{Si}-\mathrm{N}$ ( $\mathrm{Si} 2+)$ and $\mathrm{SiO}_{2}(\mathrm{Si} \mathrm{4+)}$ bonded network respectively while the fourth peak could not be identified $[30,43]$. The spectrum showed a large and symmetric peak of $\mathrm{Si}-\mathrm{N}$ binding accompanied by two small peaks of $\mathrm{Si}-\mathrm{C}$ and $\mathrm{SiO}_{2}$ bonded network. It denotes that with nitrogen plasma treatment, nitrogen has substituted a considerable amount of carbon in $\mathrm{Si}-\mathrm{C}$ bonds resulting in the formation of $\mathrm{Si}-\mathrm{N}$ bonds. It indicates the stronger affinity of silicon towards nitrogen compared to carbon. Chen et al. has also observed higher affinity of silicon towards $\mathrm{Si}-\mathrm{N}$ bonds than $\mathrm{Si}-\mathrm{C}$ bonds in amorphous silicon carbon nitride thin films [44]. Deconvolution of N 1s spectrum (Fig. 5(f)) showed the existence of four peaks at 397.3, 398.1, 399.0 and $399.7 \mathrm{eV}$. The peak at $397.3 \mathrm{eV}$ are attributed to $\mathrm{Si}-\mathrm{N}$ binding, while the peak position at 398.4, 399.1 and $400 \mathrm{eV}$ are assigned to $\mathrm{sp}^{3} \mathrm{C}-\mathrm{N}, \mathrm{sp}^{2} \mathrm{C} \equiv \mathrm{N}$ and sp $\mathrm{C}-\mathrm{N}$ bonded network respectively $[30,40,41]$. The $\mathrm{N} 1 \mathrm{~s}$ spectrum also indicates that incorporated nitrogen was preferentially bonded with carbon as $\mathrm{sp}^{2} \mathrm{C}=\mathrm{N}$ and $\mathrm{sp} \mathrm{C} \equiv \mathrm{N}$ compared to $\mathrm{sp}^{3} \mathrm{C}-\mathrm{N}$ and $\mathrm{Si}-\mathrm{N}$ bonding. The elemental composition of $\mathrm{N}_{2}$ plasma treated $\mathrm{Si}-$ DLC films (Table 1) showed that there is significant reduction in carbon concentration coupled with an increase in silicon and nitrogen concentration with $\mathrm{N}_{2}$ plasma treatment. It denotes that nitrogen plasma treatment seemed to substitute a considerable amount of carbon and resulted in the formation of $\mathrm{C}=\mathrm{N}$, $\mathrm{C} \equiv \mathrm{N}, \mathrm{C}-\mathrm{N}$ and $\mathrm{Si}-\mathrm{N}$ bonded network on the surface.

The XPS spectra of Si-DLC films after $\mathrm{O}_{2}$ plasma treatment were shown in Fig. 5(g), (h) and (i). The $\mathrm{C} 1 \mathrm{~s}$ spectrum (Fig. 5 (g)) was deconvoluted into five components at 284.4, 285.1, 286.6, 288.5 and $293.5 \mathrm{eV}$. These peak positions are assigned to the binding energy of $\mathrm{C}=\mathrm{C}, \mathrm{C}-\mathrm{C}, \mathrm{C}-\mathrm{O}, \mathrm{C}=\mathrm{O}$ bonded network and $\pi$-excitation respectively $[25-29,45]$. The ratio of the $\mathrm{C}=\mathrm{C}$ to $\mathrm{C}-\mathrm{C}$ bonds was similar to that of the untreated $\mathrm{Si}-$ DLC film shown in Fig. 4(a). However, $\mathrm{C}=\mathrm{O}$ peak was enhanced by the $\mathrm{O}_{2}$ plasma treatment. It must be also noted that the intensity of overall carbon peak was reduced by the plasma treatment while that of Si peak increased. The $\mathrm{O}_{2}$ plasma has etched away a considerable amount of carbon, whereas the $\mathrm{Si}$ in the film accumulates on the surface in the oxide form during the plasma treatment. Consequently, there is significant rise in oxygen and silicon concentration on the surface as can be seen in Table 1. 
Table 2

Chemical bonds and compounds present on the surfaces of Si-DLC films and plasma treated Si-DLC films and their corresponding water contact angles and surface energies

\begin{tabular}{|c|c|c|c|c|c|}
\hline \multirow[t]{2}{*}{ Films } & \multirow[t]{2}{*}{ Chemical bonds and compounds present on surface (XPS analysis) } & \multirow{2}{*}{$\begin{array}{l}\text { Water contact } \\
\text { angle (degree) }\end{array}$} & \multicolumn{3}{|l|}{ Surface energy $(\mathrm{dyn} / \mathrm{cm})$} \\
\hline & & & Dispersive component & Polar component & Total \\
\hline Si-DLC & $\mathrm{C}=\mathrm{C}, \mathrm{C}-\mathrm{C}, \mathrm{C}-\mathrm{O}, \mathrm{Si}-\mathrm{C}, \mathrm{Si}_{2} \mathrm{O}_{3}, \mathrm{SiO}_{2}$ & $70.1 \pm 3.0$ & $28.6 \pm 5.2$ & $11.1 \pm 3.7$ & $39.7 \pm 8.9$ \\
\hline Si-DLC $\left(\mathrm{H}_{2}\right.$ treated $)$ & $\mathrm{C}=\mathrm{C}, \mathrm{C}-\mathrm{C}, \mathrm{C}-\mathrm{O}, \mathrm{Si}-\mathrm{C}, \mathrm{Si}_{2} \mathrm{O}_{3}, \mathrm{SiO}_{2}$ & $42.1 \pm 6.0$ & $67.2 \pm 1.8$ & $29.9 \pm 3.5$ & $12.3 \pm 2.5$ \\
\hline $\mathrm{Si}-\mathrm{DLC}\left(\mathrm{CF}_{4}\right.$ treated $)$ & $\mathrm{C}=\mathrm{C}, \mathrm{C}-\mathrm{C}, \mathrm{C}-\mathrm{CF}_{n}, \mathrm{CF}-\mathrm{CF}_{n}, \mathrm{CF}_{2}, \mathrm{CF}_{3}, \mathrm{Si}-\mathrm{C}, \mathrm{Si}_{2} \mathrm{O}_{3}, \mathrm{SiO}_{2} \mathrm{CF}_{n}$ & $92.1 \pm 2.6$ & $29.9 \pm 3.6$ & $1.9 \pm 1.1$ & $31.8 \pm 2.5$ \\
\hline Si-DLC $\left(\mathrm{N}_{2}\right.$ treated $)$ & $\mathrm{C}=\mathrm{C}, \mathrm{C}-\mathrm{C}, \mathrm{C}=\mathrm{N}, \mathrm{C} \equiv \mathrm{N}, \mathrm{C}-\mathrm{N}, \mathrm{CO}, \mathrm{Si}-\mathrm{C}, \mathrm{Si}-\mathrm{N}, \mathrm{SiO}_{2}$ & $42.7 \pm 3.7$ & $26.1 \pm 3.2$ & $30.3 \pm 4.7$ & $56.4 \pm 1.7$ \\
\hline Si-DLC $\left(\mathrm{O}_{2}\right.$ treated $)$ & $\mathrm{C}=\mathrm{C}, \mathrm{C}-\mathrm{C}, \mathrm{C}-\mathrm{O}, \mathrm{C}=\mathrm{O}, \mathrm{Si}-\mathrm{C}, \mathrm{Si}_{2} \mathrm{O}_{3}, \mathrm{SiO}_{2}$ & $13.4 \pm 1.3$ & $18.0 \pm 0.3$ & $53.1 \pm 0.8$ & $71.0 \pm 1.1$ \\
\hline
\end{tabular}

Deconvolution of Si $2 p$ spectra showed the existence of three peaks at 101, 102.4 and $103.1 \mathrm{eV}$ (Fig. 5(h)). These peaks corresponds to the $\mathrm{Si}$ binding energies in $\mathrm{Si}-\mathrm{C}(\mathrm{Si} 1+), \mathrm{Si}_{2} \mathrm{O}_{3}$ $(\mathrm{Si} 3+)$ and $\mathrm{SiO}_{2}(\mathrm{Si} 4+)$ respectively $[28,30]$. The $\mathrm{Si}-\mathrm{C}$ peak was also found to shift towards higher energy in this case. The $\mathrm{Si} 2 \mathrm{p}$ spectrum indicates that with $\mathrm{O}_{2}$ plasma treatment, oxygen has substituted most of the carbon in $\mathrm{Si}-\mathrm{C}$ bonded network leading to the formation of $\mathrm{Si}_{2} \mathrm{O}_{3}$ and $\mathrm{SiO}_{2}$. The $\mathrm{O}$ 1s spectra (Fig. 5(i)) was deconvoluted into two components at 531.7 and $532.5 \mathrm{eV}$ which was attributed to the binding energy of oxygen in $\mathrm{C}=\mathrm{O}$ and $\mathrm{SiO}_{2} / \mathrm{C}-\mathrm{O}$ bonded network respectively $[30,45]$. The XPS spectra denotes that oxygen was incorporated into the Si-DLC films partially as $\mathrm{C}=\mathrm{O}, \mathrm{C}-\mathrm{O}$ bonded network and the rest as $\mathrm{SiO}_{x}$ like network. The peak position of $\mathrm{SiO}_{2}$ bonding is coincident with that of $\mathrm{C}-\mathrm{O}$ bond. So the peak at $532.5 \mathrm{eV}$ has contribution of both $\mathrm{SiO}_{2}$ and $\mathrm{C}-\mathrm{O}$ bonded network.

Table 2 summarized the chemical bonds and compounds present on the surfaces of Si-DLC and plasma treated Si-DLC films and their corresponding surface energies. Both chemical bonds and surface energy are not varied by the $\mathrm{H}_{2}$ plasma treatment. Due to high electronegativity of fluorine, more energy will be required to take out an electron from the core level of fluorine. This results in high binding energy and stable covalent bond between carbon and fluorine. Though $\mathrm{C}-\mathrm{F}$ bond is highly dipolar due to its large dipole moment, the net dipole moment of $\mathrm{CF}_{3}, \mathrm{CF}_{2}$ and $\mathrm{CF}-\mathrm{CF}$ bonding structures is very small due to geometrical structure. In addition, $\mathrm{C}-\mathrm{F}$ bond is relatively nonpolarizable so that hydrogen bonding to $\mathrm{C}-\mathrm{F}$ dipoles is not generally observed in polar solvents like water [46]. Consequently, incorporation of fluorine in carbon network reduced the polar component in the surface energy, which resulted in a hydrophobic surface. $\mathrm{C}-\mathrm{N}$ and $\mathrm{Si}-\mathrm{N}$ bonds are polar in nature with a difference in electronegativity of 0.5 and 1.2 Pauling units respectively [47]. The presence of $\mathrm{C}-\mathrm{N}$ and $\mathrm{Si}-\mathrm{N}$ bonds in the surface of $\mathrm{N}_{2}$ plasma treated samples gives rise to higher polar component in its surface energy. The surface of $\mathrm{O}_{2}$ plasma treated Si-DLC films contains $\mathrm{C}-\mathrm{O}$ and $\mathrm{Si}-\mathrm{O}$ bonds both of which are highly polar with a difference in electronegativity of 1.0 and 1.7 Pauling unit respectively. This explained the high surface energy and hydrophilic nature of $\mathrm{O}_{2}$ plasma treated Si-DLC films. Some $\mathrm{OH}(\mathrm{Si}-\mathrm{OH})$ groups are also expected to be present on the surfaces of $\mathrm{O}_{2}$ plasma treated Si-DLC films which might have contributed in increasing the polar component [48]. However, the $\mathrm{OH}$ groups are difficult to detect in the XPS spectra.

\subsection{Interfacial tension with human blood}

In modern clinical practice, there is a growing demand of biomaterials for various blood contacting applications. Hemocompatibility of a biomaterial is known to depend on its specific surface properties and its interaction in presence of blood [49-51]. Especially, interfacial tension between blood and biomaterials has been considered as one of the major physical properties that governs the hemocompatibility of the materials [51]. In human body, the interfacial tension between the blood plasma and the blood vessel wall or the cellular elements such as red blood cell is found to be in the order of $1-3 \mathrm{dyn} / \mathrm{cm}$ [51]. It has been indicated that if the interfacial tension between blood and biomaterial is in the same order of magnitude, hemocompatibility can be improved [51]. The blood/biomaterial interfacial tension can be determined by using the polar and dispersive components of total surface energy of human blood (phase 1) and the biomaterial surface (phase 2) according to the equation [49]:

$\gamma_{12}=\left(\alpha_{1}-\alpha_{2}\right)^{2}+\left(\beta_{1}-\beta_{2}\right)^{2}$

where $\alpha_{1}, \alpha_{2}$ and $\beta_{1}, \beta_{2}$ are the square root of the dispersive and polar component of surface energies of human blood (phase 1) and biomaterial surfaces (phase 2) respectively (as defined in Eq. (9)). $\alpha$ and $\beta$ values of human blood are 3.3 and $6.0 \mathrm{dyn}^{1 / 2} /$ $\mathrm{cm}^{1 / 2}$ respectively [52]. Fig. 6 showed the blood/biomaterial

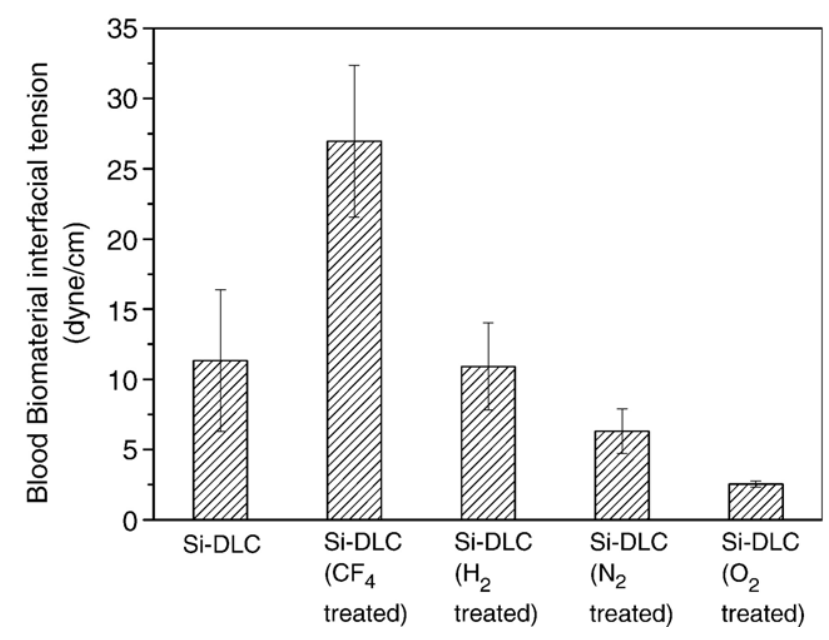

Fig. 6. Blood biomaterial interfacial tension of Si-DLC and plasma treated Si-DLC films. 
interfacial tension of Si-DLC and plasma treated Si-DLC samples obtained by Eq. (10). The $\mathrm{O}_{2}$ plasma treated Si-DLC samples revealed a low interfacial tension of $2.6 \mathrm{dyn} / \mathrm{cm}$, while higher values were obtained for $\mathrm{CF}_{4}$ and $\mathrm{H}_{2}$ plasma treated SiDLC films. The $\mathrm{O}_{2}$ plasma treated Si-DLC films would provide the surface with improved hemocompatibility compared to the other samples, if the criteria proposed by Ref. [51] is accepted.

\section{Conclusions}

The surface modification of Si-DLC films by using plasma of various gases like $\mathrm{N}_{2}, \mathrm{O}_{2}, \mathrm{H}_{2}$ and $\mathrm{CF}_{4}$ has a significant effect on its surface energy and surface chemical bonds. The plasma treatment of the Si-DLC films resulted in a hydrophilic surface for $\mathrm{N}_{2}$ and $\mathrm{O}_{2}$ plasma treated surface and a hydrophobic surface for $\mathrm{CF}_{4}$ plasma treated one. The surface wettability appears to be closely related to the polar component of the surface energy, which is governed by the polarizability of the surface chemical bonds. XPS studies revealed the presence of $\mathrm{C}=\mathrm{N}, \mathrm{C} \equiv \mathrm{N}, \mathrm{C}-\mathrm{N}$ and $\mathrm{Si}-\mathrm{N}$ bonds on the surface of $\mathrm{N}_{2}$ plasma treated Si-DLC films, $\mathrm{C}=\mathrm{O}$, $\mathrm{C}-\mathrm{O}, \mathrm{SiO}_{2}$ and $\mathrm{Si}_{2} \mathrm{O}_{3}$ bonded network on the surface of $\mathrm{O}_{2}$ plasma treated Si-DLC films and $\mathrm{C}-\mathrm{CF}_{n}, \mathrm{CF}-\mathrm{CF}_{n}, \mathrm{CF}_{2}$ and $\mathrm{CF}_{3}$ bonds on the surfaces of $\mathrm{CF}_{4}$ plasma treated Si-DLC films. The interfacial tensions of the plasma treated samples with human blood revealed that the $\mathrm{O}_{2}$ plasma treated Si-DLC films is as low as $2.6 \mathrm{dyn} / \mathrm{cm}$, which would provide a surface with improved hemocompatibility.

\section{Acknowledgement}

This research was supported by a grant (code \#: 06K150101610) from 'Center for Nanostructured Materials Technology' under '21st Century Frontier R\&D Programs' of the Ministry of Science and Technology, Korea and TaeWoong Medical Co., Korea.

\section{References}

[1] A. Grill, Diamond Relat. Mater. 8 (1999) 428

[2] J.S. Chen, S.P. Lau, B.K. Tay, G.Y. Chen, Z. Sun, Y.Y. Tan, G. Tan, J.W. Chai, J. Appl. Phys. 89 (2001) 7814.

[3] A. Weinss, G. Persch-Schuy, R. Hartmann, P. Joeris, J. Vac. Sci. Technol. A 18 (2000) 2023.

[4] T. Nakamura, T. Ohana, M. Suzuki, M. Ishihara, A. Tanaka, Y. Koga, Surf. Sci. 580 (2005) 101.

[5] R. Hauert, Diamond Relat. Mater. 12 (2003) 583.

[6] R.K. Roy, K.-R. Lee, J. Biomed. Mater. Res. Part B: Appl Biomater (in press), doi:10.1002/jbm.b.30768.

[7] S.L. Maeng, S. Uchikoga, F.J. Cough, A. Tagliaferro, A.J. Flewitt, J Robertson, W.I. Milne, Diamond Relat. Mater. 9 (2000) 805.

[8] S. Meskinis, V. Kopustinskus, K. Slapikas, S. Tamuleviscius, A. Guobieny, R. Gudaitis, V. Grigaliunas, Thin Solid Films 515 (2006) 636.

[9] G. Francz, A. Schroeder, R. Hauert, Surf. Interface Anal. 28 (1999) 3.

[10] A.-Y. Wang, H.-S. Ahn, K.-R. Lee, J.-P. Ahn, Appl. Phys. Lett. 86 (2005) 111902 .

[11] V. Singh, V. Palshin, R.C. Tittsworth, E.I. Meletis, Carbon 44 (2006) 1280.
[12] K.-R. Lee, M.-G. Kim, S.-J. Cho, K.Y. Eun, T.-Y. Seong, Thin Solid Films 308-309 (1997) 263.

[13] S. Grigull, R. Behrisch, S. Parascandola, J. Nucl. Mater. 275 (1999) 158

[14] J. Barz, M. Haupt, U. Vohrer, H. Hilgers, C. Oehr, Surf. Coat. Technol. 200 (2005) 453.

[15] S.-J. Park, K.-R. Lee, D.H. Ko, Tribol. Int. 37 (2004) 913.

[16] H.-G. Kim, S.-H. Ahn, J.-G. Kim, S.J. Park, K.-R. Lee, Thin Solid Films 482 (2005) 299.

[17] S.J. Park, K.-R. Lee, D.-H. Ko, International Conference on Metallurgical Coatings and Thin Films, April 19-23, 2004, San Diego, California, E4-18, 2004, p. 54.

[18] T.I.T. Okpalugo, A.A. Ogwu, P.D. Maguire, J.A.D. McLaughlin, Biomaterials 25 (2004) 239.

[19] S. Zhang, H.J. Du, S.E. Ong, K.N. Aung, H.C. Too, X.G. Miao, Thin Solid Films, 515 (2006) 66.

[20] D.K. Owens, J. Appl. Polym. Sci. 13 (1969) 1741

[21] F.M. Fowkes, J. Phys. Chem. 67 (1963) 2538.

[22] R.J. Good, L.A.J. Girifalco, J. Phys. Chem. 64 (1960) 561

[23] C.J. van Oss, M.K. Chaudhury, R.J. Good, Chem. Rev. 88 (1988) 927.

[24] P.M. Sherwood, in: D. Briggs, M.P. Seah (Eds.), Practical Surface Analysis by Auger and X-ray Photoelectron Spectroscopy, Wiley, New York, 1983.

[25] P. Merel, M. Tabbal, M. Chaker, S. Moisa, J. Margot, Appl. Surf. Sci. 136 (1998) 105

[26] T. Mikami, H. Nakazawa, M. Kudo, M. Mashita, Thin Solid Films 488 (2005) 87.

[27] F.R. Mc Feely, S.P. Kowalczyk, L. Ley, R.G. Cavell, R.A. Pollak, D.A. Shirley, Phys. Rev. B 9 (1974) 5268.

[28] Y.H. Ichikawa, Phys. Rev. 109 (1958) 653.

[29] A.P. Dementjev, A. de Graaf, M.C.M. van de San n, K.I. Maslakov, A.V. Naumkin, A.A. Serov, Diamond Relat. Mater. 9 (2000) 1904.

[30] J. Chastain (Ed.), Handbook of X-ray Photoelectron Spectroscopy, PerkinElmer Corporation, Minnesota, 1992.

[31] A. Toth, I. Bertoti, G. Marletta, G.G. Ferenczy, M. Mohai, Nucl. Instrum. Methods B 116 (1996) 299.

[32] E. Atanassova, D. Spassov, A. Paskaleva, K. Kostov, Appl. Surf. Sci. 253 (2006) 2841.

[33] G.Q. Yu, B.K. Tay, Z. Sun, L.K. Pan, Appl. Surf. Sci. 219 (2003) 228.

[34] C.H. Lai, W.S. Lai, H.J. Chen, S.Y. Chang, S.J. Lin, Thin Solid Films 510 (2006) 125.

[35] N. Ariel, M. Eizenberg, Y. Wang, S.P. Murarka, Mater. Sci. Semiconductor Processing 4 (2001) 383.

[36] M.S. Silverstein, L. Sandrin, E. Sacher, Polymer 42 (2001) 4299

[37] M. Grischke, A. Hieke, F. Morgenweck, H. Dimigen, Diamond Relat Mater. 7 (1998) 454.

[38] R.E. Sah, B. Dischler, A. Bubenzer, P. Koidl, Appl. Phys. Lett. 46 (1985) 739.

[39] S. Arai, K. Tsujimoto, S. Tachi, Jpn. J. Appl. Phys. 31 (1992) 2011.

[40] S. Bhattacharyya, C. Cardinaud, G. Turban, J. Appl. Phys. 83 (1998) 4491.

[41] M. Tabbal, P. Merel, S. Moisa, M. Chaker, A. Ricard, M. Moisan, Appl. Phys. Lett. 69 (1996) 1698.

[42] A. Mansour, D. Ugolini, Phys. Rev. B 47 (16) (1993) 10201.

[43] I. Bertoti, Surf. Coat. Technol. 151-152 (2002) 194.

[44] C.W. Chen, C.C. Huang, Y.Y. Lin, L.C. Chen, K.H. Chen, Diamond Relat. Mater. 14 (2005) 1126.

[45] X.L. Zhu, S.B. Liu, B.Y. Man, C.Q. Xie, D.P. Chen, D.Q. Wang, T.C. Ye, M. Liu, Appl. Surf. Sci. 253 (2007) 3122.

[46] J.C. Biffinger, H.W. Kim, S.G. DiMagno, Chem. Bio. Chem. 5 (2004) 622.

[47] L.Y. Chen, F.C.N. Hong, Diamond Relat. Mater. 12 (2003) 968.

[48] A. Kanta, R. Sedev, J. Ralston, Langmuir 21 (2005) 2400.

[49] D.H. Kaelble, J. Moacanin, Polymer 18 (1977) 475.

[50] H.T. Spijker, R. Graaff, P.W. Boonstra, H.J. Busscher, W. van Oeveren, Biomaterials 24 (2003) 4717.

[51] E. Ruckenstein, S.V. Gourisankar, J. Colloid Interface Sci. 101 (1984) 436.

[52] S.C.H. Kwok, J. Wang, P.K. Chu, Diamond Relat. Mater. 14 (2005) 78. 